\title{
Cellular Organization of an Antennal Mechanosensory Pathway in the Cockroach, Periplaneta americana
}

\author{
John A. Burdohan and Christopher M. Comer \\ Neuroscience Group, Department of Biological Sciences, University of Illinois at Chicago, Chicago, Illinois 60607
}

\begin{abstract}
Escape responses of cockroaches, Periplaneta americana, can be triggered by wind and mediated by a group of "giant interneurons" that ascend from cercal mechanoreceptors to motor centers. Recently it has been observed that escape also can be triggered by tactile stimulation of the antennae, and it is then independent of the giant interneurons. Here we identify a descending antennal mechanosensory pathway that may account for escape. Cobalt backfills demonstrated that a limited number of cells in the head ganglia have axons that project through all three thoracic ganglia. Comparison with known wind-sensory pathways indicated that wind is not a reliable stimulus for activating descending antennal pathways. However, direct touch stimulation of an antenna reliably evoked short-latency responses in cells with axons in the cervical connectives. Intracellular recording and dye injection revealed members of this
\end{abstract}

Recent experiments suggest that many orienting behaviors can be controlled by more than one neural pathway. Usually, this is related to the need to integrate information from more than one sensory modality. Some clear examples are found in the control of orienting movements of head and body by visual or somatosensory inputs in frogs (Comer and Grobstein, 1981), the control of head movements in owls by visual or acoustic inputs (DuLac and Knudsen, 1990), and the triggering of eye and/or head movements in mammals by visual or auditory signals (Jay and Sparks, 1987; Stein et al., 1989). These examples are all from vertebrates, and mainly they have provided insights into sensory control of movement at the systems level. We describe here a new group of uniquely identifiable invertebrate neurons that are involved in multisensory control of directional movement.

Several decades of work have shown that, when the escape response of cockroaches is triggered by wind, it is mediated by several pairs of giant interneurons (GIs), which transmit signals from cercal wind receptors to thoracic motor centers (Roeder, 1967; Camhi, 1984; Ritzmann, 1993). The GIs encode information on the direction of wind stimuli (Westin et al., 1977; Camhi and Levy, 1989), which is then translated into directional motor output: animals pivot away from a wind puff and then run (Camhi and Tom, 1978; Camhi and Levy, 1988; Nye and Ritzmann, 1992). The

Received Feb. 21, 1996; revised June 21, 1996; accepted June 25, 1996.

This work was supported by grants from the National Science Foundation (BNS8909051 and IBN-9222619) to C.M.C. We thank Dr. Sasha Zill for kindly providing samples of piezoelectric bimorphs; J. King, J. Larimer, and W. J. Thompson for reading an earlier version of this manuscript; and $\mathrm{S}$. B. for encouragement.

Correspondence should be addressed to Dr. Christopher M. Comer, Department of Biological Sciences (M/C 066), University of Illinois at Chicago, 845 West Taylor Street, Chicago, IL 60607.

Dr. Burdohan's present address: Department of Neurobiology and Anatomy, University of Texas Medical School, Houston, TX 77225.

Copyright (C) 1996 Society for Neuroscience $0270-6474 / 96 / 165830-14 \$ 05.00 / 0$ pathway, referred to as descending mechanosensory interneurons (DMls). The two axons of largest diameter in the cervical connectives were found to belong to DMls, and these largecaliber interneurons were studied in detail. One had a soma in the supraesophageal ganglion, and the other in the subesophageal ganglion. Both had extensive neuritic arborizations at the same level as the soma and axonal arbors in all three thoracic ganglia. Each of these DMls exhibited short-latency responses to small antennal movements, demonstrated a degree of directional sensitivity, and rapidly conducted impulses to thoracic levels. These cells have properties suggesting that they play a role in a short-latency behavior such as touch-evoked escape.

Key words: antennae; cockroach, escape behavior; interneurons; sensory coding; touch

idea that information in the GIs determines the direction of evasive turning responses is supported directly by lesion experiments. Selective removal of one or more GIs with Pronase shifts the direction of wind-evoked turning (Comer, 1985; Comer and Stubblefield, 1988; Comer and Dowd, 1993) in a manner consistent with control of escape by a specific ensemble of GIs (Camhi, 1988; Comer and Dowd, 1988; Levi and Camhi, 1994).

Despite the evidence for control of escape by the wind-sensory GIs, cockroaches are capable of producing escape responses after elimination of all GI axons ascending to motor centers (Comer et al., 1988; Stierle et al., 1994). These "non-GI" responses depend on receptors associated with the antennae (Comer et al., 1988), indicating that there are also descending neural pathways carrying sensory information to thoracic motor centers. Behavioral experiments have indicated that this descending antennal pathway is touch-sensory and is used for evading small predators not detected by the wind-sensory system (Comer and Dowd, 1993; Comer et al., 1994).

Preliminary work revealed the existence of descending interneurons (Burdohan and Comer, 1990) that responded to touching the antennae. The present study examines properties of specific cells in the descending system by using anatomical and physiological methods. We report here that two uniquely identifiable interneurons in the descending pathway have the largest caliber axons in the cervical connectives and properties suggesting that they play an important role in generating antennal touch-evoked evasive behavior. Further support for the hypothesis is provided by experiments that show that the firing patterns of these interneurons in behaving animals are correlated with evasive turning behavior (Ye and Comer, 1996; companion paper, this issue). This work begins comparison of cellular architecture and coding mecha- 
nisms within two neural pathways related to a well defined orienting movement.

\section{MATERIALS AND METHODS}

All animals were adult male Periplaneta americana, obtained from our own breeding colonies or purchased from suppliers. For both anatomical and physiological experiments, an animal first was anesthetized with carbon dioxide and, after removal of its legs and wings, pinned out on a paraffin-coated platform. An incision was made along the dorsal midline extending from the abdomen to the anterior edge of the pronotum. The cuticle was spread apart and pinned to expose the thoracic cavity. The gut was excised, and muscles and connective tissue overlying the ventral nerve cord (VNC) were removed. During the course of an experiment, the VNC was perfused continuously with saline (Callec and Sattelle, 1973).

Anatomical demonstration of descending interneurons. Cobalt backfills were performed to determine whether significant numbers of cells in the brain (supraesophageal ganglion, Sa) and the subesophageal ganglion (Sb) had axons projecting to thoracic levels. The nerve cord was cut between the second and third thoracic ganglia (T2 and T3), and the anterior cut end of either one or both connectives was placed in a Vaseline well constructed inside the thoracic cavity. A few drops of a $4 \%$ solution of cobalt hexamine chloride were placed in the well, which was then covered with Vaseline. After allowing time for transport, the presence of cobalt was demonstrated as described below.

In experiments to reveal anatomical details of individual descending interneurons, a wax-coated metal platform was placed under the cervical connectives [or the connectives between the first thoracic ganglion (T1) and T2], and individual axons were impaled with microelectrodes made from glass capillary tubing. The electrodes were filled with a $4 \%$ cobalt hexamine chloride solution containing $0.4 \%$ fast green and had resistances of 20-60 M $\Omega$. Electrical signals were amplified and displayed via conventional methods.

After a cell was penetrated, it was tested for responses to mechanical stimulation of the antennae (see below). Responsive cells were pressureinjected with cobalt. Pressure was applied in pulses (Picospritzer, General Valve, Fairfield, NJ) until a green longitudinal profile was visible within the cord. After allowing time for dye travel appropriate to a single-cell fill (2-3 $\mathrm{hr}$ at room temperature) or a connective backfill $\left(1-2 \mathrm{~d}\right.$ at $\left.5^{\circ} \mathrm{C}\right)$, the two head ganglia and the three thoracic ganglia were removed and fixed in Carnoy's or $10 \%$ formalin. In the case of single-cell fills, silver intensification of the tissue was performed according to the method of Bacon and Altman (1977). The tissue then was dehydrated via an alcohol series and cleared. Individual ganglia were viewed under a compound microscope, and cells were drawn with a camera lucida. To determine the location of dendritic and axonal arborizations with respect to known fiber tracts, we embedded some ganglia in paraffin and serially sectioned them.

In all descriptions that follow, references to the laterality of stimulation, the position of soma, and the location and extent of major arborizations are with respect to the side of the nerve cord on which the axon of a cell is located. All drawings are represented by the orientation scheme advocated by Strausfeld et al. (1984). In an intact animal, the supraesophageal ganglion (Sa) is oriented at an angle with respect to the remainder of the CNS that courses parallel to the longitudinal body axis. In this paper, Sa will be viewed as if it were rotated downward and in the same plane as the rest of the CNS, i.e., the posterior surface of Sa in the intact animal will be considered here its dorsal surface. The terminology of Tyrer and Gregory (1982) will be used for fiber tracts in the thoracic ganglia.

Physiological analysis of descending interneurons. Extracellular recordings were made with hook electrodes constructed from Teflon-coated silver wire. A region of the $\mathrm{VNC}$ was lifted onto the hook, and the recording site was insulated with a mixture of petroleum jelly and mineral oil. Electrical signals were amplified and displayed on an oscilloscope for on-line observation and stored on magnetic tape for later analysis. Intracellular recordings were made with glass microelectrodes, filled with $4 \%$ Lucifer yellow, and backfilled with $1 \mathrm{~m}$ lithium chloride, having final resistances of $60-120 \mathrm{M} \Omega$. After a cell was penetrated, it was tested for its response to a number of stimuli (see below). In addition to sensory tests, a conduction velocity was derived by backfiring an impulse via an extracellular electrode placed on the T2-T3 connective. By measuring the time of arrival of the impulse at the recording electrode and the distance between the two electrodes, a value was calculated for this parameter. After completion of a testing session, dye was iontophoresed into the cell using 3-5 nA of constant, hyperpolarizing current for 15-30 min. Then the nerve cord was extracted, fixed, embedded in paraffin, and serially sectioned. The sections were viewed on a compound microscope using epifluorescent illumination, and representative sections were photographed and/or drawn.

Wind stimuli. Two types of wind-generating devices were used. Both devices were built in our laboratory. The first type was used initially to examine descending unit activity driven by wind. It consisted of a piston encased in a plastic housing $(22 \mathrm{~cm}$ inner diameter). The piston was held in an upward position by a set of springs. A lever arm connected to a rotary solenoid depressed the piston when the solenoid was triggered by an electrical pulse. This apparatus produced wind puffs with a peak velocity of $1.8-2.0 \mathrm{~m} / \mathrm{sec}$ and an acceleration of $22 \mathrm{~m} / \mathrm{sec}^{2}$. Wind velocity was measured with a hot-wire anemometer (Flowtronic 55A1).

The second device was similar in design to the wind machine described by Westin et al. (1977). It used a rotary solenoid to depress a lever against a rubber membrane stretched over the wide end of a plastic funnel. This device was adjustable to enable tests of the relative wind sensitivities of the descending and ascending interneuronal pathways. Two wind velocities were generated: "high" winds $(1.8-2.0 \mathrm{~m} / \mathrm{sec}$ peak velocity and 25 $\mathrm{m} / \mathrm{sec}^{2}$ acceleration) and "low" winds $(0.3-0.7 \mathrm{~m} / \mathrm{sec}$ peak velocity and $\sim 10 \mathrm{~m} / \mathrm{sec}^{2}$ acceleration). The low winds were produced by restricting the travel of the lever arm, thus reducing the depression of the membrane. In both devices, the resultant wind was funneled through a series of plastic tubes $(4 \mathrm{~cm}$ inner diameter) that ended at an opening $3 \mathrm{~cm}$ in front of the animal.

Touch stimuli. Some mechanical stimuli were delivered by hand-held glass probes. However, to tap (and deflect) the flagellar segments of an antenna by controlled amounts, a piezoelectric device [rectangular bimorph (PZT-5H, Vernitron)] was used (Zill and Moran, 1981). One end was clamped in a Plexiglas holder, and a glass probe $(10 \mathrm{~cm}$ in length) was attached to the free end. With applied voltage, a range of deflection amplitudes from $0.01-1.0 \mathrm{~mm}$ was obtained. The deflection at a particular voltage was calibrated by observing the probe tip under a microscope with an ocular micrometer. The free end of the probe was positioned immediately adjacent to an antenna near the base of the flagellum. Voltage pulses were applied to the bimorph with an Anapulse stimulator (Model 301-T, WPI, Sarasota, FL). Because piezoelectric elements vibrate when voltage pulses with fast rise times are applied, an electronic frequency filter was interposed between the bimorph and the stimulator (Corey and Hudspeth, 1980).

Because the antennae actively move, it was necessary to restrain them partially to stimulate them in a standardized manner during intracellular recording experiments. Plaster of Paris was applied to cover the joint between the head and the first basal segment (the scape) and between the scape and the second segment (the pedicel). The joint between the pedicel and the flagellum was not covered. After the plaster dried, each flagellum was oriented at an angle of $\sim 45^{\circ}$ with respect to the horizontal and midline vertical axes, a position the flagella often assume in alert animals. The levels of descending activity evoked by mechanical stimulation seemed to be reduced somewhat by eliminating active movements in this way, because higher levels of activity can be evoked under experimental conditions that lack such restraint (Ye and Comer, 1996). Thus, until more is known about the nature of the antennal mechanoreceptors that provide input to descending interneurons (see Discussion), it must be noted that restraint probably caused some underestimation of the effects of antennal stimulation on interneurons.

In addition to touch stimulation of the antennae, cells were tested for their responsiveness when other sites were touched with a fine-tipped camel hair brush. Structures tested in this manner included the head hairs, mouthparts, dorsally and laterally situated hairs on the thorax and abdomen, and the cerci.

Other stimuli. Cells also were tested, although less rigorously, for their responsiveness to visual stimuli. These tests included room lights $\mathrm{ON}$ and OFF, as well as hand-held stimuli (black cardboard squares mounted at the end of a Plexiglas rod) passed in various directions within an animal's visual field. These same stimuli have been effective at eliciting visual responses from other descending interneurons in previous studies (Ye and Comer, 1994).

Data analysis. Most routine spike counting was accomplished by digitizing electrical activity from recording sessions previously stored on VHS tape, with the aid of a data acquisition board (Model TL-1, Axon Instruments, Foster City, CA) and programs written in our lab (by A. Keegan). The board sampled at $10 \mathrm{kHz}$ per channel. The analysis programs counted the number of impulses in each record and determined the latency to onset of the first impulse after stimulus presentation. In extracellular recording experiments, units were counted only if they 
occurred within $70 \mathrm{msec}$ of the arrival of a wind puff at the animal and only if they were of large amplitude ( $>25 \%$ of the maximal amplitude observed).

\section{RESULTS}

\section{The descending interneuron population}

Because cockroach escape can be controlled by receptors associated with the antennae, we sought to identify neural pathways that
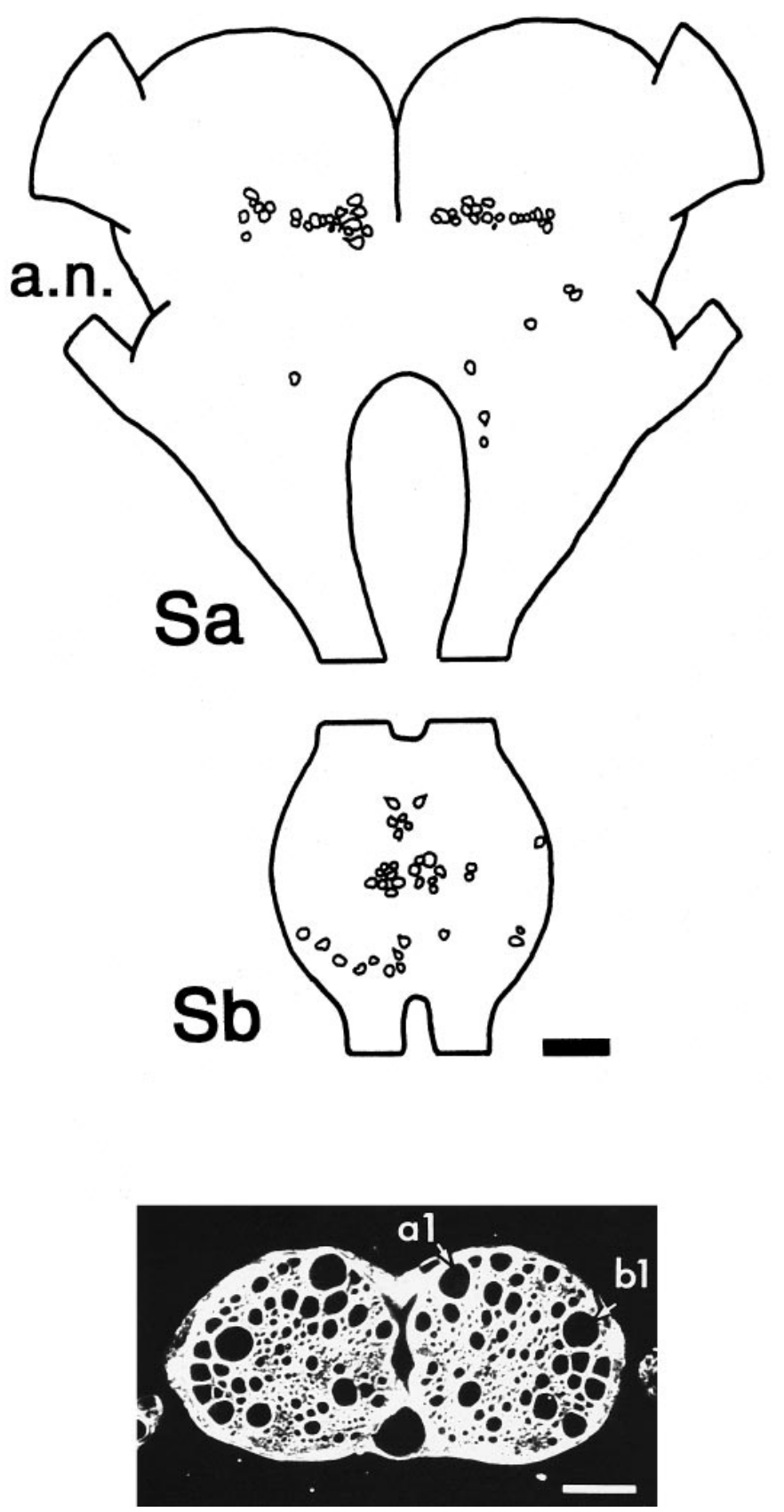

Figure 1. Axons in the cervical connectives include a population of interneurons with somata in the head ganglia and projections through the thoracic ganglia. Top, Camera lucida reconstruction of position of cobaltfilled cell bodies seen in whole mounts of head ganglia viewed from the dorsal surface. Anterior is toward the top. Cobalt was applied to both left and right connectives below the mesothoracic ganglion. $S a$, Supraesophageal ganglion; $S b$, subesophageal ganglion; a.n., antennal nerve. Bottom, Cross section through the cervical connectives viewed in phase contrast. The two largest axons (labeled $a 1$ and $b 1$ ) are those of individually identifiable interneurons that respond to antennal mechanosensory stimulation, as described in the text. Scale bar in both panels, $100 \mu \mathrm{m}$. might transmit information from the head to thoracic motor centers. The distribution of cell bodies in the head ganglia with descending axons was mapped after application of cobalt to the connectives between the second and third thoracic ganglia (T2T3). Successful fills were reconstructed in three different animals.

All backfills displayed the same distribution of labeled cell bodies; Figure 1 (top) shows a reconstruction from the preparation that demonstrated the largest number of labeled cell bodies. There were $\sim 50$ labeled somata in the supraesophageal ganglion (Sa) and $\sim 35$ somata in the subesophageal ganglion (Sb). Both connectives were exposed to cobalt in this preparation, so a minimum estimate would be that $\sim 40-45$ axons on each side of the VNC arise from cells of the head ganglia and project as far as T3. In Sa, most labeled cells were grouped together in the protocerebrum, approximately at the level of the posterior aspect of the
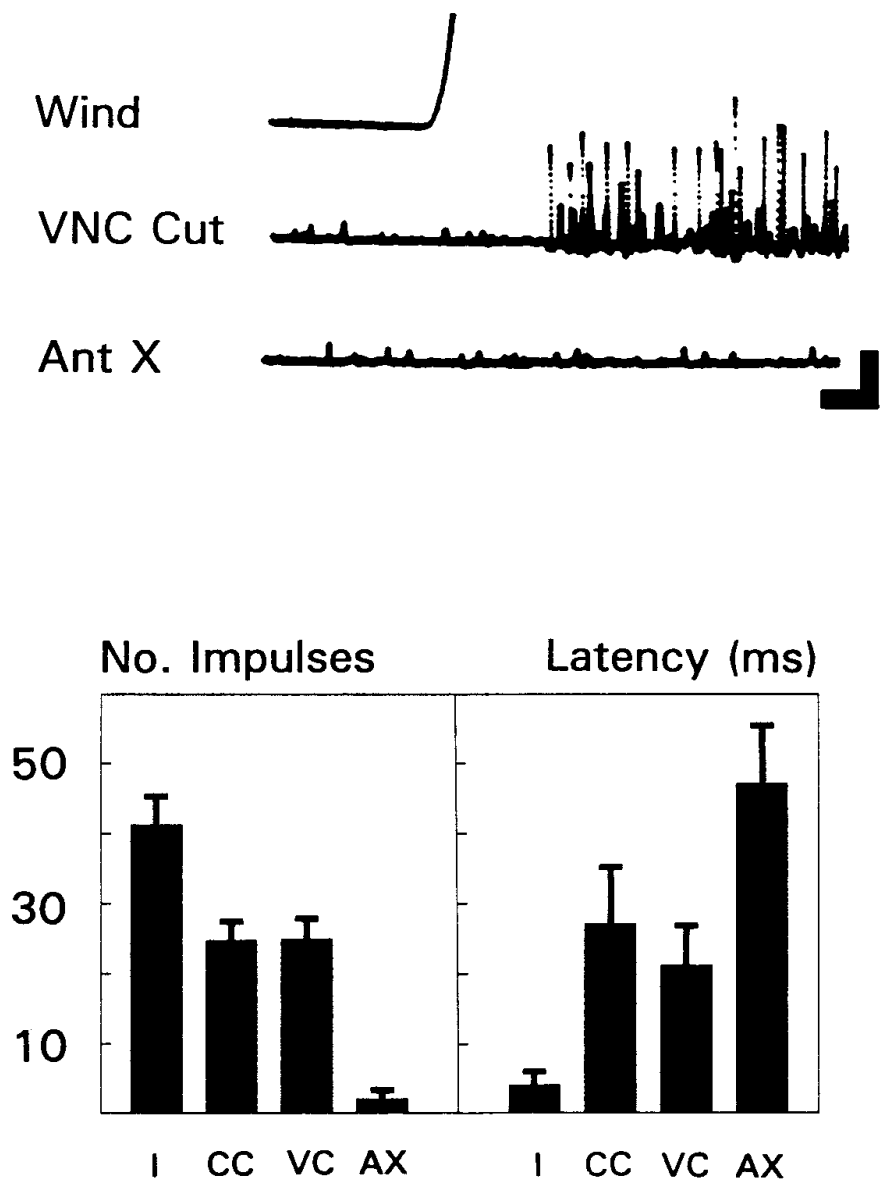

Figure 2. Many units recorded at the cervical level represent descending signals related to the antennae. Top, Wind-evoked multiunit activity recorded extracellularly from the cervical connective. Wind had a peak velocity from 1.8 to $2.0 \mathrm{~m} / \mathrm{sec}$. VNC Cut, Response after transecting the ventral nerve cord at the level of A1-A2; Ant $X$, response after cutting off both antennae at the pedicel. Calibration: vertical, $2 \mathrm{mV}$; horizontal, 10 msec. Bottom, Summary of all experiments performed on six animals. Histogram on left gives mean number of impulses recorded at cervical level. Height of bar for each condition was derived by averaging responses for each animal and then calculating the grand mean across animals \pm SEM. Only large amplitude impulses were counted, i.e., those $\geq 25 \%$ of the maximum amplitude observed, and only those that occurred within 70 msec of wind onset. Histogram on right gives mean latency in milliseconds to first impulse across the same six animals \pm SEM. Total number of trials averaged $=230$. Conditions: $I$, intact; $C C$, after covering the cerci; $V C$, after cutting the VNC between abdomen and thorax; $A X$, after removing both antennae. 
optic lobes. Only a few other cell bodies were labeled, and these were scattered widely in the deutocerebrum and the tritocerebrum. In Sb, labeled cell bodies were concentrated near the ventral midline of that ganglion, with just a few positioned laterally and toward the dorsal surface.

The physiological analysis of descending pathways was performed at the level of the cervical connectives. Figure 1 (bottom) shows a cross section through the connectives; each contains a large number of axons, including profiles of numerous largecaliber axons (diameters between 20 and $60 \mu \mathrm{m}$ ). The two largest axons (labeled a1 and b1) belong to cells of the descending antennal pathway and will be described below in detail.

\section{Descending mechanosensory pathways differ from ascending wind-sensory pathways}

Under certain conditions, wind can activate descending interneurons. However, there are several features that distinguish this
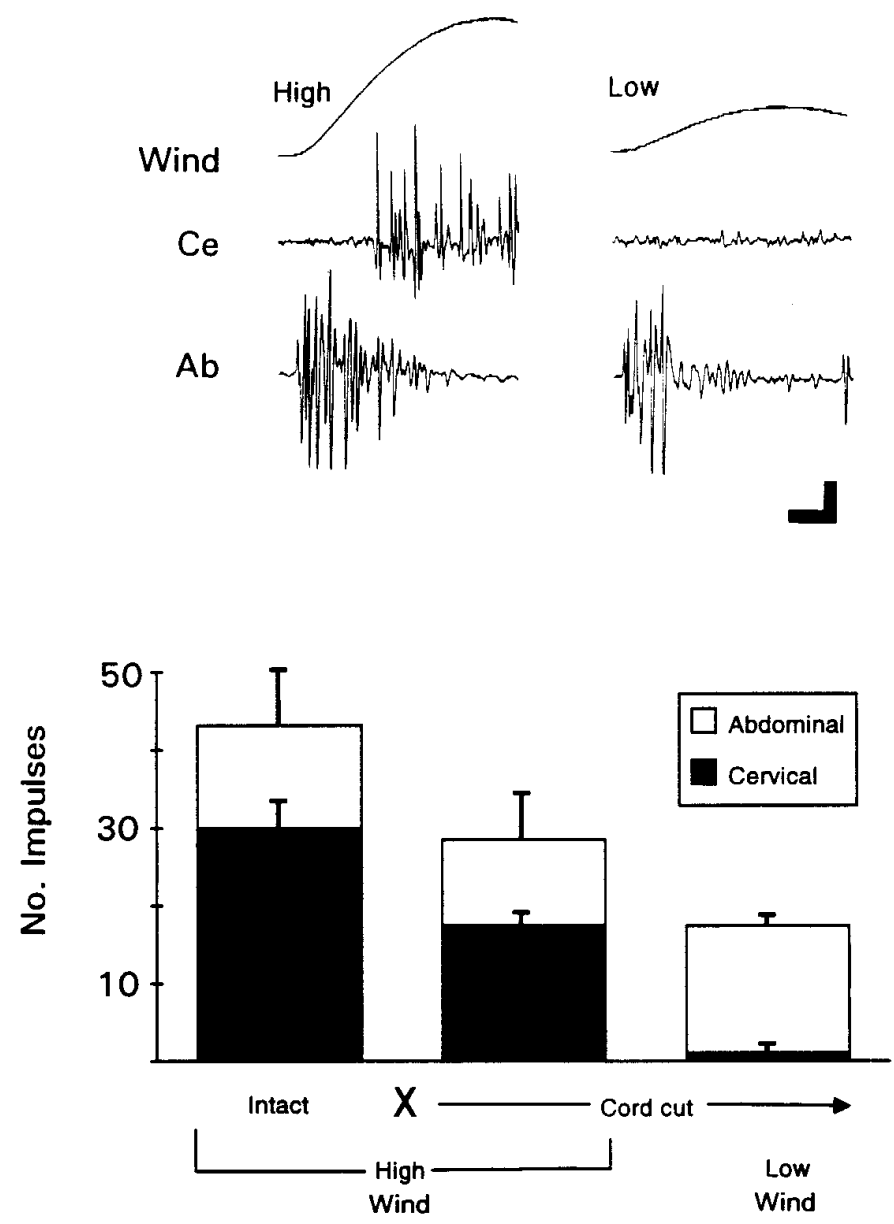

Figure 3. Descending units are less responsive to wind than units of the ascending cercal wind-sensory system. Top, Wind-evoked, multiunit activity recorded simultaneously at cervical $(C e)$ and abdominal $(A b)$ levels. Nerve cord was cut between abdomen and thorax. Wind puffs of two different peak velocities were used. High (left), 1.8-2.0 m/sec; Low (right), 0.3-0.7 m/sec. Calibration: vertical, $2 \mathrm{mV}$; horizontal, $20 \mathrm{msec}$. Bottom, Summary of all experiments performed on three animals. Height of bar for each condition gives mean number of large impulses recorded simultaneously at cervical (black bars) and abdominal (open bars) level. Averages for each condition were derived by averaging responses for each animal and then calculating the grand mean across animals \pm SEM. Total number of trials averaged $=93$. No. Impulses, Number of large impulses counted (criteria as in Fig. 2). Conditions: Intact, Before cutting the VNC; $X$-Cord cut $\rightarrow$, after cutting the VNC; High Wind, Low Wind, wind puffs with peak velocities as described above. wind-evoked activity from that of the GIs. Typically, a burst of large amplitude multiunit activity can be evoked in the cervical connectives at short latency in response to a wind puff of high velocity and acceleration (see Materials and Methods). This could be descending activity, ascending activity, or both. To clarify the origin of the activity, GI input was eliminated either by covering the cerci with a mixture of petroleum jelly and mineral oil or by transecting the VNC between the thorax and the abdomen. After these procedures, impulse activity still could be evoked by wind at the cervical level (Fig. 2, top, VNC Cut). The remaining activity essentially was abolished after removal of both antennae (Fig. 2, top, Ant $X$ ). The results from six animals are summarized in Figure 2 (bottom). Note that eliminating GI (or GI-related) input was associated with an increase in the latency of the response to wind (from $\sim 5$ to $\sim 25 \mathrm{msec}$ ). These results suggest that wind puffs (at least those of high velocity and acceleration) activated at least two systems passing through the cervical connectives: an ascending system (on the basis of the cercal covering results, this may include the rostral-most projections of the GIs) and a descending (antennal) system.

To distinguish better the activity of ascending and descending interneurons elicited by wind, we made simultaneous extracellular recordings at the level of the cervical and abdominal connectives of the VNC. (The large amplitude wind-evoked impulses observed in extracellular recordings from the abdominal connectives are known from numerous studies to be those of the GIs.) Activity, then, was evoked either with a standard wind similar to that already used (high intensity wind; high peak velocity and acceleration as indicated in Materials and Methods) or a low intensity wind (lower in both peak velocity and acceleration).

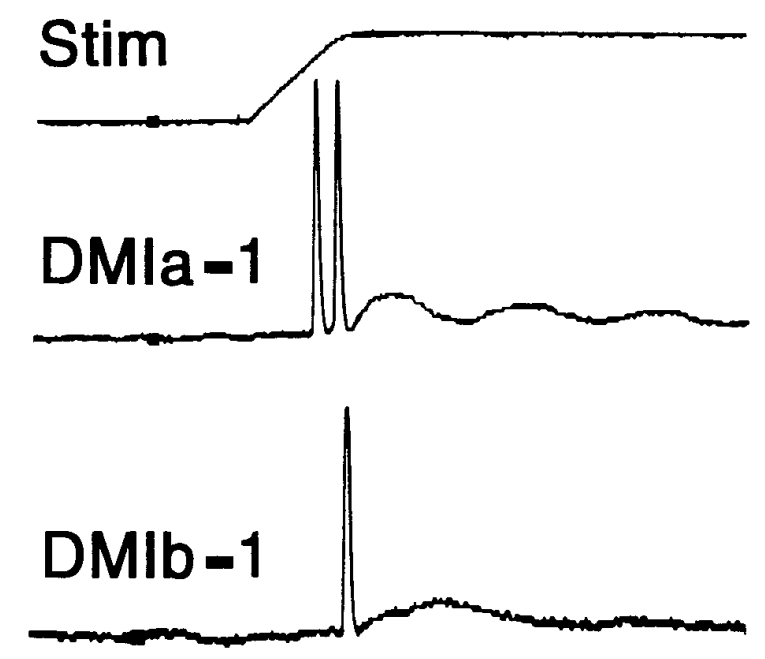

Figure 4. The largest diameter cervical axons are those of interneurons that produce short-latency phasic responses to antennal touch. Intracellular recordings were made from DMI axons in the cervical connective. The records show the response of two cells (identified as DMIs, corresponding to the axons labeled in Fig. 1, bottom) to a $1.0 \mathrm{~mm}$ deflection of an antenna lasting $1 \mathrm{sec}$ (top trace, monitor of voltage to piezoelectric crystal). For DMIa-1, the contralateral antenna was tapped from the lateral direction (deflecting the flagellum medially). For DMIb-1, the contralateral antenna was tapped from the front direction (deflecting the flagellum backward). These directions can be considered optimal for each cell (see Fig. 12). Calibration: vertical, $40 \mathrm{mV}$ (intracellular records only); horizontal, $10 \mathrm{msec}$. 
Figure 3 (top) shows that, after isolating thoracic and abdominal portions of the VNC, activity was recorded at both levels in response to an intense wind. However, after lowering the wind intensity, activity at the cervical level essentially was abolished. Also note that direct comparison of the latencies at these two sites demonstrates that the GIs respond to wind much more quickly than descending interneurons. The results from three animals are summarized in Figure 3 (bottom). The low intensity wind used here is one that is still substantially above threshold for escape behavior (Camhi and Nolen, 1981). Thus, by comparison with the GI pathway, descending units activated here should not be regarded as part of a sensory system for which wind is the adequate stimulus. The observation that descending interneurons respond to wind at relatively long latencies provides further support for this idea, especially because tactile stimulation of the antennae reliably activates descending interneurons at very short latencies, i.e., within 5-10 msec of stimulus onset (Fig. 4; Burdohan and Comer, 1990). The latency of the touch-evoked response suggests that such units represent rapidly conducting descending interneurons, which receive relatively direct input from rostral mechanoreceptors.

\section{The structure of individual descending interneurons}

To determine the location and structure of interneurons with these touch-sensory properties, the thoracic connectives were probed with microelectrodes. Cells that were activated by tapping an antenna were filled with cobalt. A number of cells were encountered that had axons descending from the head ganglia and responded to direct mechanical stimulation of one or both antennae. They will be referred to, operationally, as descending mechanosensory interneurons (DMIs). These interneurons will be differentiated further on the basis of their ganglion of origin: DMIa for those with a cell body located in Sa, and DMIb for those with a soma in $\mathrm{Sb}$.

\section{The largest DMIs}

The main focus of this study was to identify neurons that could play a role in generating antennal touch-evoked evasive behavior. Hence, attention was concentrated on mechanosensory cells that were capable of rapid conduction to thoracic motor centers. As seen in Figure 1 (bottom), two axons in each cervical connective are conspicuously larger in diameter than any others. When cross sections were examined from preparations with individual cells filled with cobalt, it was immediately clear that these axons are those of DMIs. The more medial axon is that of a DMIa, and the lateral axon is that of a DMIb. Because these are the first DMIs of each class to be studied in detail, they will be referred to as DMIa-1 and DMIb-1, respectively (labeled in Fig. 1, bottom). Each of these DMIs has been recorded from, and filled, in at least 40 separate experiments. As described below, each interneuron is uniquely identifiable, based on anatomical criteria, and each responds in a characteristic way to touching one or both antennae. [As indicated in Materials and Methods, references to the laterality of stimulation and to anatomical features are with respect to the side of the nerve cord on which the axon of a cell is located. Other descending interneurons, with smaller axons and various
Figure 5. Anatomy of DMIa-1 in the head ganglia. Camera lucida drawings show dorsal (left) and lateral (right) whole-mount views in both head ganglia ( $S a$ and $S b$ as indicated). Cell in this and subsequent figures labeled by intracellular injection of cobalt hexamine. Anterior is toward the top. In lateral view, dorsal is to the left. a.n., Antennal nerve. Scale bars: $S a, 150 \mu \mathrm{m} ; S b, 100 \mu \mathrm{m}$.
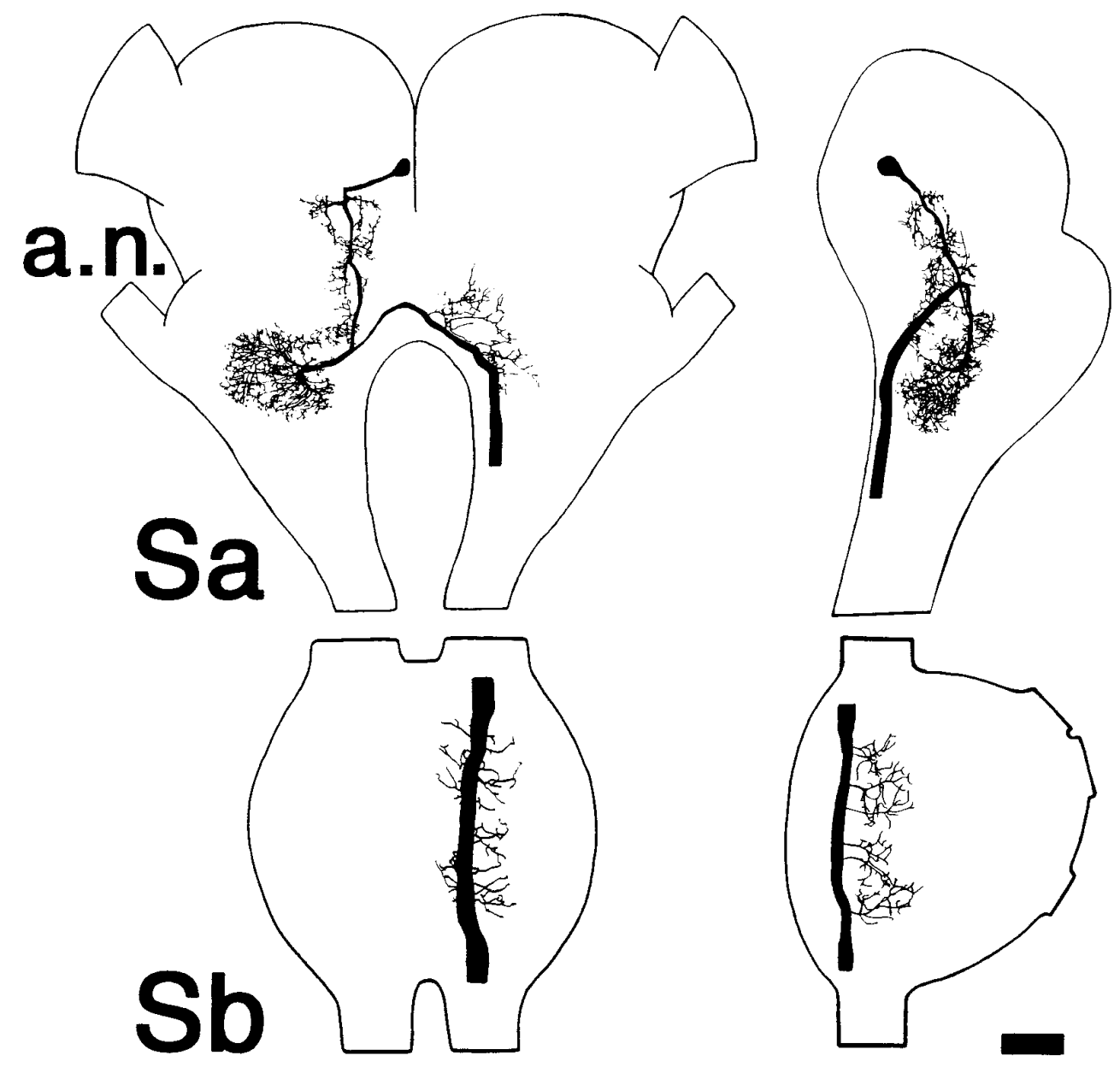
sensory properties, will be described elsewhere (Burdohan et al., unpublished data).]

\section{General sensory properties and structure of DMla-1}

DMIa-1 exhibited a short-latency phasic response to direct mechanical stimulation of the contralateral antenna (Fig. 4). Mechanical stimulation of the ipsilateral antenna and other sensory structures of the body, including the cerci and head hairs, failed to elicit a response. Visual stimuli also were ineffective in activating this interneuron.

The cell body of a- 1 is located in Sa near the medial surface of the contralateral protocerebrum midway between the dorsal and ventral surfaces (Fig. 5). The primary neurite extends posteriorly toward the dorsal surface into the deutocerebrum, giving off numerous fine branches along its extent. On the cell body side of the ganglion, the neurite gives off an extensive arborization that encompasses much of the posterior portion of the deutocerebrum, dorsal to, but not including, the antennal lobe.

The neurite continues its course near the dorsal surface to the ipsilateral side of $\mathrm{Sa}$, where it becomes thicker and gives off a number of ventrolaterally directed branches on its course to the circumesophageal connective. In $\mathrm{Sb}$, the axon gives off primarily ventrolaterally directed branches as it continues posteriorly into
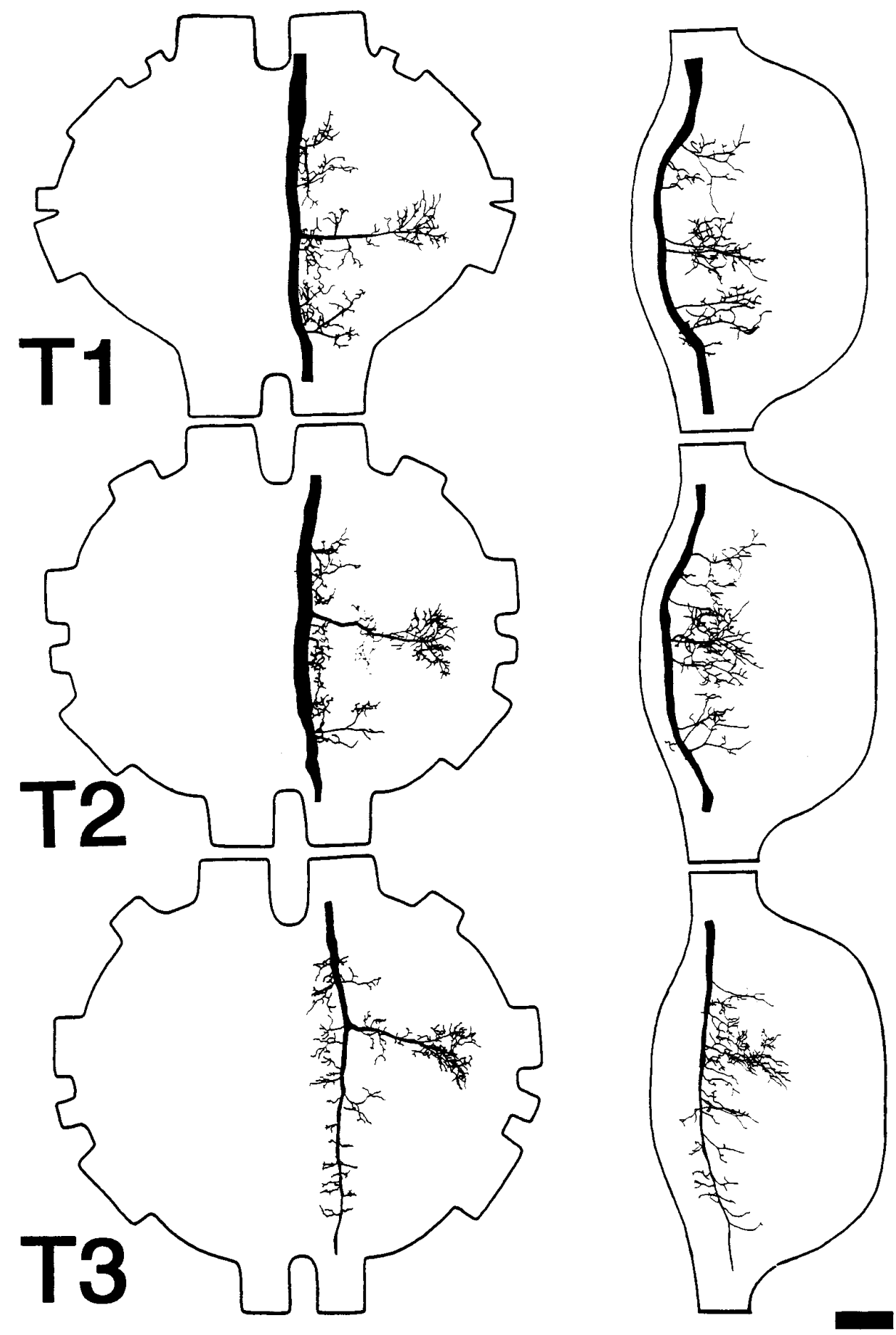

Figure 6. Anatomy of DMIa-1 in the thoracic ganglia. Camera lucida drawings show dorsal (left) and lateral (right) whole-mount views in each of the three thoracic ganglia (T1-T3, as indicated). Anterior is toward the top. In lateral view, dorsal is to the left. Scale bar, $100 \mu \mathrm{m}$. 
the cervical connective. In the thorax (Fig. 6), the branching pattern is similar in all three ganglia. A prominent lateral branch is given off that arborizes extensively in the peripheral portion of each ganglion, and a number of shorter lateral branches are also given off. As seen in lateral view, all of the branches are confined to the dorsal half of the ganglia. The axon has been observed to course at least as far as the first abdominal ganglion (data not shown).

\section{General sensory properties and structure of DMIb-1}

DMIb-1 also exhibited a short-latency phasic response to direct mechanical stimulation of the antennae (Fig. 4). However, unlike a-1, b-1 received input from both antennae. In addition, mechanical stimulation of the head hairs and mouthparts also elicited a response in b-1 (data not shown). Mechanical stimulation of other body regions, including the cerci, failed to activate b-1, as did visual stimuli.

The cell body of b- 1 is located on the ventrolateral surface of $\mathrm{Sb}$ near the posterior limit of the contralateral hemiganglion (Fig. 7), corresponding to the labial neuromere. The primary neurite courses dorsally and medially to cross the midline. During this course, it gives off a number of branches on either side of the midline that arborize extensively throughout the dorsal region of the ganglion. As the neurite approaches the ipsilateral peripheral extent of the ganglion, it splits into ascending and descending branches. The narrow ascending branch courses along the lateral margin of the ganglion, giving off a number of medially directed branches. The descending branch expands in caliber and courses posteriorly. In the thorax (Fig. 8), the branching pattern is similar in all three ganglia. Three prominent lateral branches are given off that arborize extensively along their course to the peripheral limits of each ganglion, and numerous medioventrally directed branches are given off that approach, but do not cross, the ganglionic midline. The axon of this cell also has been observed to continue posteriorly at least as far as the first abdominal ganglion (data not shown).

\section{Anatomical uniqueness of DMla-1 and DMIb-1}

Although a-1 typically exhibited slight variations in structure in different animals, the overall branching pattern of this neuron was the same in all animals; this was true of b-1, as well. An example of this is shown for the pattern of each cell in T2 (Fig. 9). This anatomical similarity of each DMI, in different animals, was seen at all levels (Sa-T3) of the VNC examined. It was always possible to distinguish these two DMIs from each other and from other descending interneurons on the basis of their anatomy. In addition, their sensory properties (e.g., which antenna provided input) always corresponded with their morphology. For these reasons, DMIa-1 and DMIb-1 are considered to be individually identifiable neurons.

Additional distinguishing features of each DMI could be observed in cross section. As shown in Figure 10, the axon of a-1 courses through the medial aspect of the medial dorsal tract $(M D T)$ in $\mathrm{T} 1$ and $\mathrm{T} 2$ (also in Sb; data not shown). However, in T3 the axon shifts ventrally to the dorsal intermediate tract $(D I T)$. Confirming what was seen in whole mount, arborizations occurred in and among the dorsal tier of fiber tracts. In addition, arborizations from the prominent lateral branch occurred in the periphery of each ganglion. The axon of b- 1 courses through the middle of the lateral dorsal tract (LDT) in T1-T3 (Fig. 10). The ascending branch in $\mathrm{Sb}$ courses within the same tract (data not shown). Similar to a-1, arborizations of b-1 occurred in and among the dorsal tier of fiber tracts, as well as in the lateral aspect of each ganglion.

\section{Characteristics of responses to antennal touch}

As noted above, impulses were recorded at the cervical level from both DMIs at very short latency after antennal stimulation (Fig. $4)$. The average response latencies $( \pm$ SD) for each DMI (under optimal conditions; see Fig. 12) were $7.1 \pm 1.0 \mathrm{msec}$ for a-1, and $8.2 \pm 0.3 \mathrm{msec}$ (contralateral antenna) or $9.9 \pm 2.4 \mathrm{msec}$ (ipsilateral antenna) for $b-1$. Within the range tested (10 msec-1 sec), stimulus duration had no effect on the number of impulses evoked (data not shown). In addition to their rapid response to antennal stimulation, both DMIs could transmit this information quickly to thoracic levels. The average estimated conduction velocity $( \pm$ SD) calculated (from a minimum of 20 trials conducted in 4 different animals) for each DMI were: $4.6 \pm 0.5 \mathrm{~m} / \mathrm{sec}$ for $\mathrm{a}-1$, and $4.7 \pm 0.2$ $\mathrm{m} / \mathrm{sec}$ for $\mathrm{b}-1$.

Neurons involved in the detection of predators via antennal contact might be expected to exhibit a high degree of sensitivity to movements of the antennae. DMIs were tested for this ability by observing their response at different amplitudes of antennal deflection. The amount of antennal deflection was controlled by varying the voltage to the bimorph, which, in turn, altered the displacement of the probe attached to its free end. However, it should be noted that the antennae were not attached to the probe, so it is possible that their actual displacement was greater than that of the probe. Hence, these results should not be interpreted as indicating an absolute threshold for response.
Figure 7. Anatomy of DMIb-1 in the subesophageal ganglion. Camera lucida drawings show dorsal (left) and lateral (right) whole-mount views in $S b$. Anterior is toward the top. In lateral view, dorsal is to the left. Scale bar, $100 \mu \mathrm{m}$.
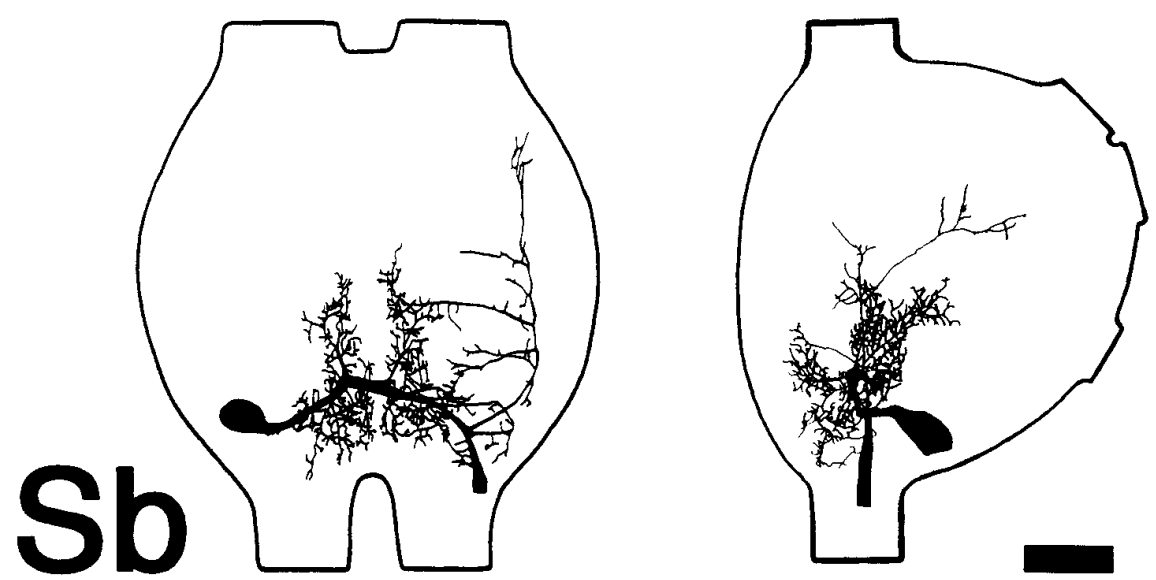


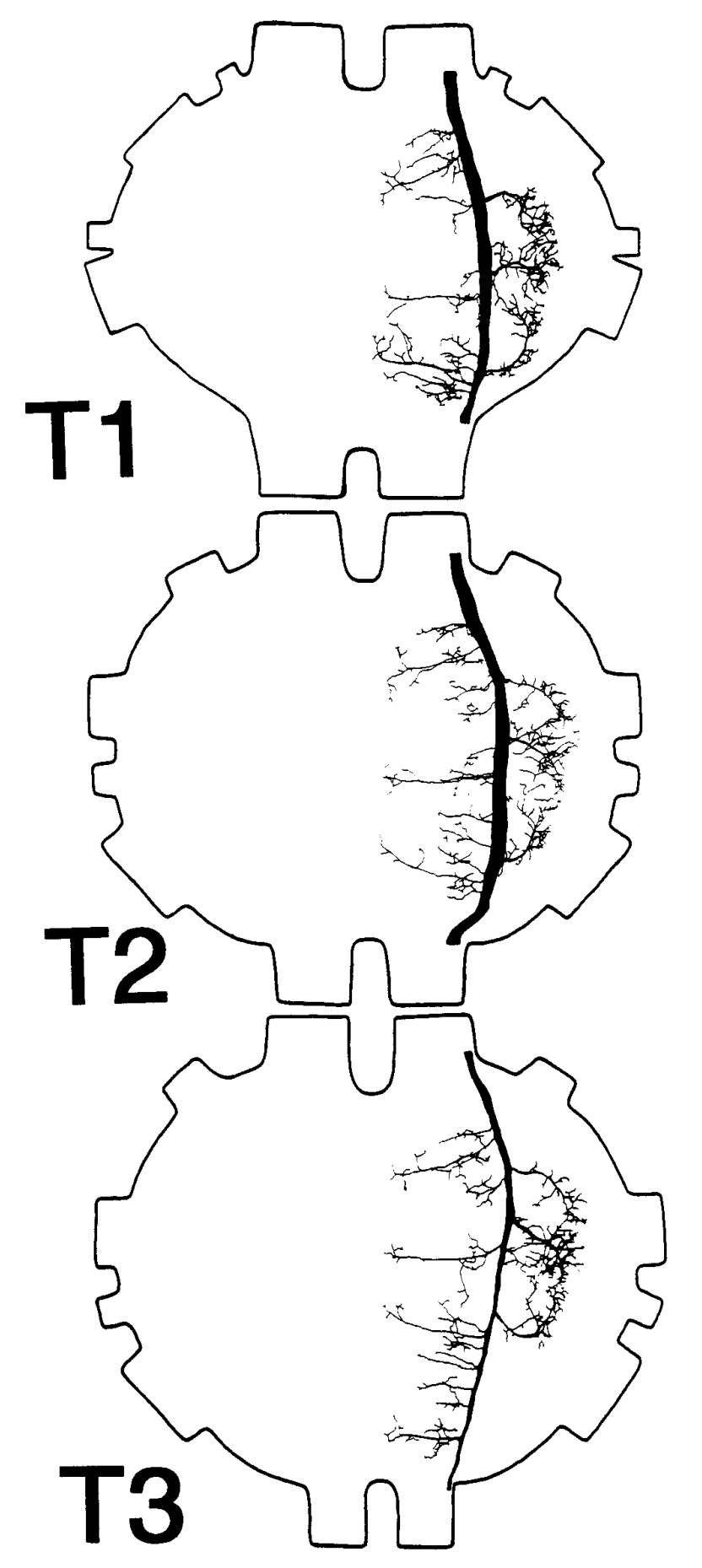

The responsiveness of both DMIs (measured as the mean number of impulses evoked across trials for each animal and at each displacement tested) varied as the antennae were displaced by different amounts (Fig. 11). DMIa-1 exhibited the greatest sensitivity, responding occasionally at the smallest displacement tested $(0.01 \mathrm{~mm})$ and very typically firing one spike in response to $0.05 \mathrm{~mm}$ deflections. As the amplitude of antennal deflection was increased further, the responsiveness of a- 1 also increased. At the largest displacements tested $(0.5$ and $1.0 \mathrm{~mm})$, the cell responded reliably with two impulses.

DMIb-1 seemed to be somewhat less sensitive than a- 1 . It did not respond to $0.01 \mathrm{~mm}$ deflections and occasionally fired for 0.05

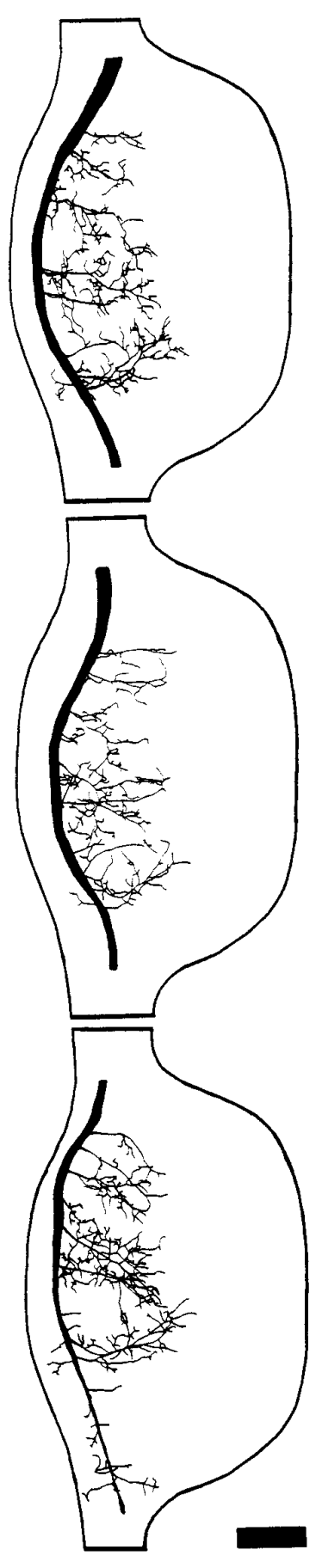

Figure 8. Anatomy of DMIb-1 in the thoracic ganglia. Camera lucida drawings show dorsal (left) and lateral (right) whole-mount views in each of the three thoracic ganglia (T1-T3). Anterior is toward the top. In lateral view, dorsal is to the left. Scale bar, $100 \mu \mathrm{m}$.

and $0.10 \mathrm{~mm}$ deflections. The responsiveness of b- 1 also increased with increases in antennal deflection, responding reliably for 0.5 and $1.0 \mathrm{~mm}$ deflections. There were no marked differences in the responsiveness of DMIb-1 that depended on which antenna was deflected. It should be noted that, at the greatest deflections tested, a characteristic difference between the two cells was maintained: there was a consistent difference in average spike rate, with a-1 firing twice as many as b-1 (Fig. 11). The latency of the response in both DMIs varied only slightly with changes in antennal displacement (data not shown).

In most experiments, mechanical stimuli were delivered to the antennae at the fastest rate attainable with the bimorph $(0.1$ 


\section{DMla-1}
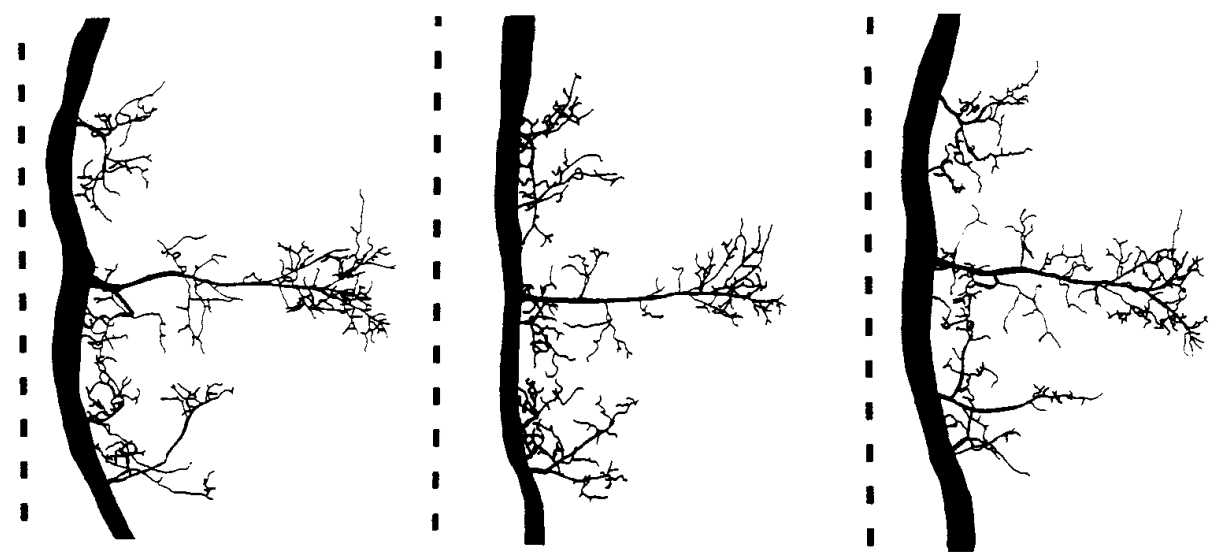

Figure 9. Anatomical constancy of DMIa-1 and DMIb-1. Camera lucida drawings of whole-mount dorsal views of three separate cobalt hexamine fills of each DMI in the mesothoracic ganglion (T2). As an aid for comparing the branching patterns, the midline of each ganglion is shown as a dashed line. An-
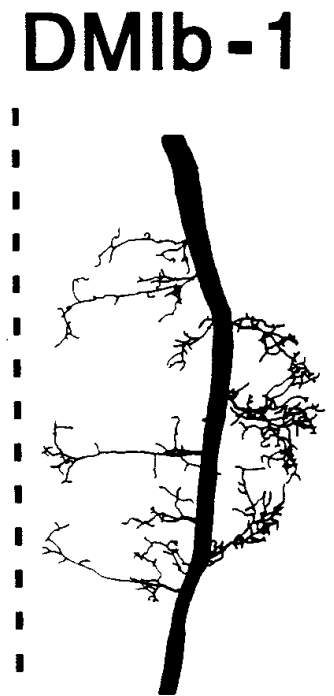
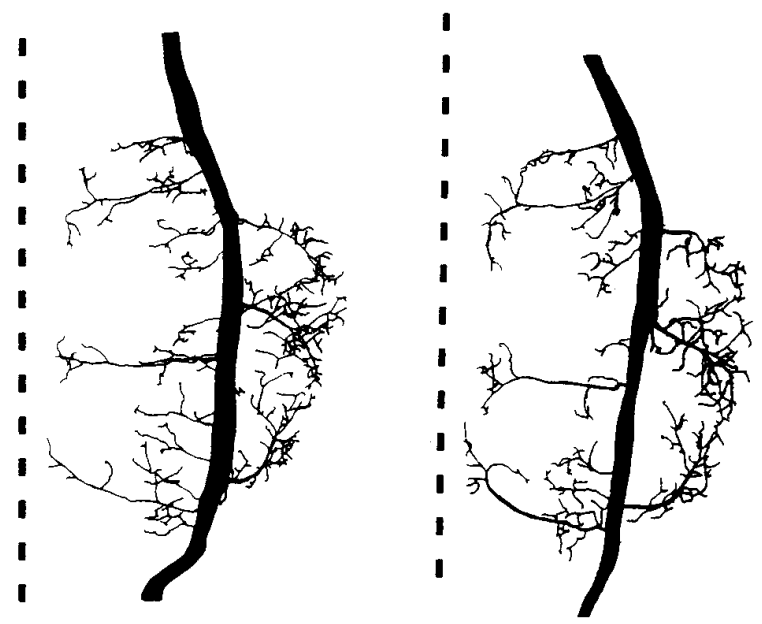

terior is toward the top. Scale bar, $100 \mu \mathrm{m}$.

$\mathrm{mm} / \mathrm{msec}$; see Materials and Methods). It is our impression that the responsiveness of both DMIs was optimized by such abrupt stimulus application. However, to describe how the DMIs are influenced by rate of antennal deflection, it will be necessary to test interneurons under conditions in which the trajectory of antennal movement is controlled more completely.

Neurons involved in generating movements directed away from a threat might be expected to exhibit some form of directional sensitivity in their responses to antennal deflection. Both DMIs were tested for this ability by observing their response to mechanical stimuli delivered to the antennae from the four basic directions around the animal (Fig. 12). The inset emphasizes that the term "direction," as used here, indicates that from which a stimulus was delivered, and it is thus opposite to the actual direction in which the antenna was displaced.

Both DMIs varied in their response to stimuli from different directions (Fig. 12). DMIa-1 was responsive for all directions from which the contralateral antenna was tapped. There was, however, a slight bias in its sensitivity. It responded with approximately two impulses, on average, to taps delivered from the front, lateral side, or rear; but responsiveness dropped to approximately one impulse for stimuli approaching from the medial side. No response was ever elicited from the ipsilateral antenna, even if tapped vigorously with a hand-held probe.

DMIb-1 responded to tapping of either antenna and was much more directional than a-1 (Fig. 12). It fired near its maximal rate (under these conditions) only to deflections from the front. With the other directions tested, the responsiveness was much lower. Deflections from the rear rarely activated the cell, so that the average spike rate was barely 0.1 impulses per trial. Deflections from the medial and lateral directions were more effective than those from the rear but still produced an average number of spikes approaching 0.5 per trial. There were no readily apparent differences in latency as a function of direction for either DMI (data not shown).

\section{DISCUSSION}

This set of experiments begins the characterization of a descending antennal mechanosensory pathway in Periplaneta americana that has some organizational and functional parallels with the ascending wind-sensory GI system. With the exception of a preliminary report (Burdohan and Comer, 1990), DMIa-1 and 

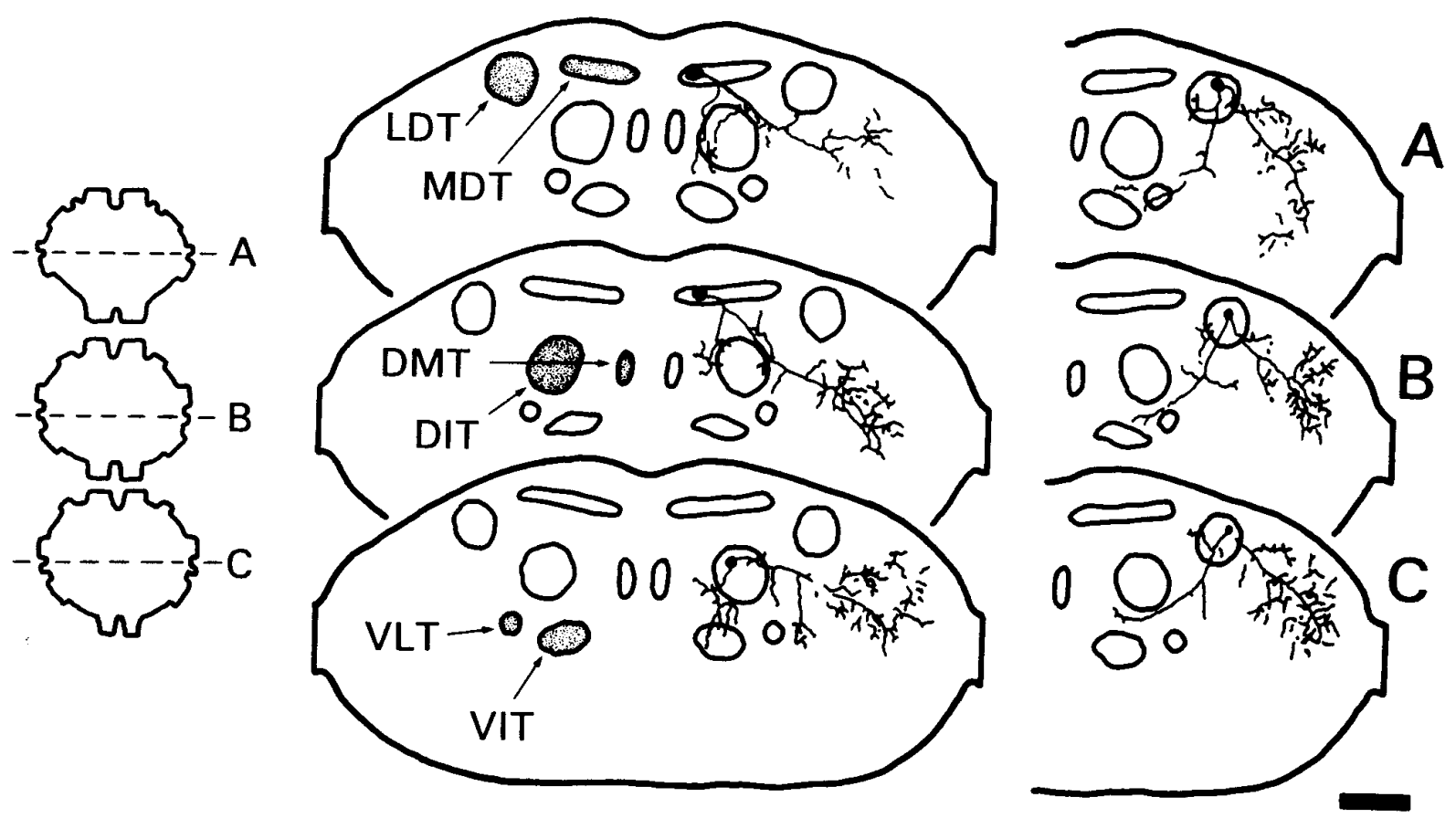

Figure 10. Distinguishing details of DMIa-1 and DMIb-1 seen in sections. Camera lucida reconstructions from transverse sections of DMIa-1 (left) and DMIb-1 (right) in the thoracic ganglia. Each drawing was constructed from five to six serial sections (12 $\mu \mathrm{m}$ thick). The level of each drawing is indicated to the left on a dorsal view of the ganglia $(A, \mathrm{~T} 1 ; B, \mathrm{~T} 2 ; C, \mathrm{~T} 3)$. Axonal arbors are shown in relation to the fiber tracts described by Tyrer and Gregory (1982): DIT, dorsal intermediate tract; $D M T$, dorsal median tract; $L D T$, lateral dorsal tract; $M D T$, median dorsal tract; VIT, ventral intermediate tract; $V L T$, ventral lateral tract. On sections, dorsal is toward the top. Scale bar, $100 \mu \mathrm{m}$.

DMIb-1 have not been described before. They have the largest axons at the cervical level ( $\sim 40-50 \mu \mathrm{m}$ in diameter) and have estimated conduction velocities between $4-5 \mathrm{~m} / \mathrm{sec}$. On the basis of axon caliber and speed of conduction, they approximate the characteristics of the abdominal GIs [40-60 $\mu \mathrm{m}$ in diameter (Roeder, 1967); 5-7 m/sec conduction velocity (Spira et al., 1969)]. In a sense, then, these two DMIs represent descending "giants" and thus are likely to play a role in generating short-latency behavioral responses.

\section{Sensory inputs and the DMI pathway}

DMI inputs seem to be exclusively mechanosensory. Both were activated by a tap to the appropriate antenna, and b-1 also was responsive to mechanical stimulation of cephalic hairs and mouthparts. Visual stimuli had no apparent effect. There are two possible sources for antennal mechanosensory input to the DMIs. First, tactile sensory receptors on flagellar segments of the antennae (Toh, 1977; Schaller, 1978) may have been activated by the wind and touch stimuli used here. Second, in insects there are several proprioceptive organs located on, or within, the basal segments of the antennae (Gewecke, 1974; Toh, 1981; Strausfeld and Bacon, 1983; Yagodin and Kovbasa, 1984) that also may have been activated by these stimuli. The two possibilities are not mutually exclusive, and studies are now underway to assess the relative importance of flagellar versus basal receptors.

Some perspective on likely contributions from different receptor types can be provided from a consideration of the morphology of individual DMIs and the central organization of antennal projections. Although few details are known, mechanoreceptors on the flagellum are believed to project primarily into the antennal lobes (Rospars, 1988; Homberg et al., 1989). As shown above, a-1 has no branches within the antennal lobes, and b-1 does not even project into Sa. Thus, if connections do exist between these
DMIs and flagellar mechanosensory neurons, they are unlikely to be direct.

Both DMIs, however, do project into regions of the head ganglia that have been shown, in related insects, to receive input from mechanoreceptors associated with basal antennal segments. Gewecke (1979) and Bräunig et al. (1983) have shown in locusts that afferent projections from these receptors terminate in regions of Sa dorsal to the antennal lobe [the antennal mechanosensory and motor center (AMMC)] (Rospars, 1988; Homberg et al., 1989), as well as in dorsal neuropilar regions of Sb. Similar projections have been demonstrated in flies (Bacon and Strausfeld, 1986). These are precisely the regions in which a- 1 and b-1 have extensive arborizations. Thus, if connections exist between these receptors and DMIs, they could be direct.

\section{Motor outputs and the DMI pathway}

Both DMIs have axonal arborizations in dorsal and lateral regions of all three thoracic ganglia. This suggests that DMIs can access the leg motor circuitry because a number of neurons related to leg control reside within or project into these regions. These include the following: (1) leg motor neurons and premotor interneurons (Ritzmann and Pollack, 1990), (2) the GIs (Stubblefield and Comer, 1989), (3) a population of nonspiking thoracic interneurons $\left(\mathrm{TI}_{\mathrm{A}} \mathrm{s}\right)$ that receive input from the GIs and drive leg motor activity (Ritzmann and Pollack, 1986), and (4) leg proprioceptors that influence the $\mathrm{TI}_{\mathrm{A}} \mathrm{s}$ (Murrain and Ritzmann, 1988). In addition, recent experiments have shown that mechanical stimulation of the antennae (as well as other sites) can generate short-latency responses in $\mathrm{TI}_{\mathrm{A}} \mathrm{s}$ (Ritzmann and Pollack, 1994). However, an intriguing DMI feature is that they have extensive projections at many levels of the CNS and could, therefore, be involved in other motor responses relating to the wings, the head, and the antennae themselves. 
Figure 11. Sensitivity of DMIa-1 and DMIb-1 to stimulus amplitude. Histogram summarizes all experiments on sensitivity performed with 19 animals. Antenna was tapped to deflect it by varying amounts. Horizontal axis (Stimulus Displacement) in $\mathrm{mm}$; vertical axis, mean number of impulses counted (Average No. Impulses) for each displacement tested. Open bars, Response of a-1 to tapping the contralateral antenna (no response was observed to tapping the ipsilateral antenna); black and gray bars, response of b- 1 to tapping the ipsilateral or contralateral antenna, respectively. Height of bar for each condition was derived by averaging responses for each animal and then calculating the grand mean across animals \pm SEM. Total number of trials averaged $=309$ (for 11 a-1 recordings) and 336 (for 8 b-1 recordings). Stimuli were presented from the optimal direction of each cell (see Fig. 12).

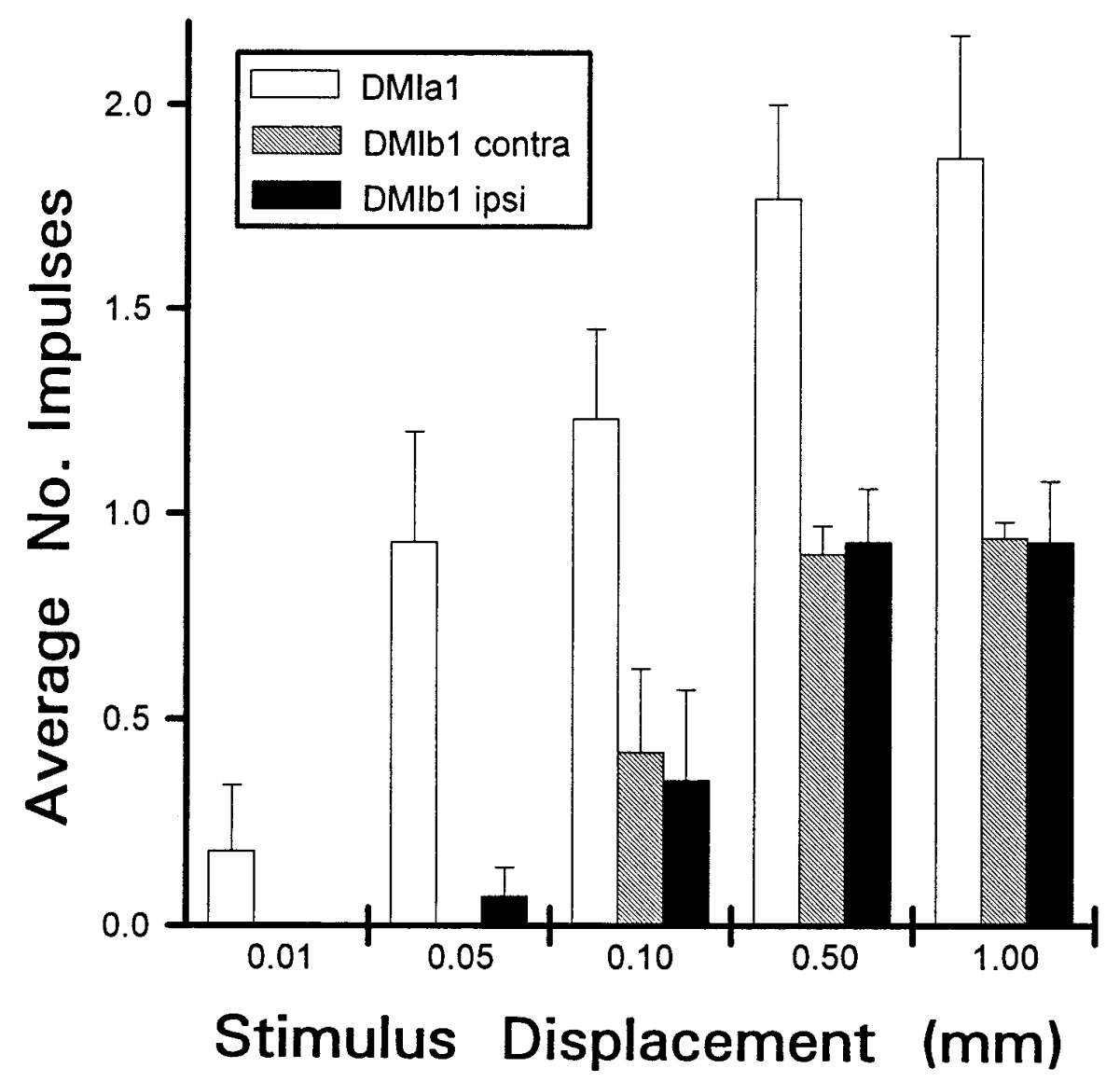

\section{Similarities between DMIs and other insect interneurons}

First, the DMIs show some similarities with previously described neurons of cockroach CNS. In particular, DMIa-1 has a similar branching pattern in the thoracic ganglia to that seen for GI-1 (Stubblefield and Comer, 1989). The shape of a-1 is also quite reminiscent of the thoracic premotor cell 701 (Ritzmann and Pollack, 1990), which receives synaptic input from wind-sensory cells such as GI-1. Thus a-1 has a structural plan that coincides with two cells already associated with cockroach escape behavior when elicited by ascending wind-sensory signals.

Descending interneurons that may play a role in generating evasive responses also have been identified in a number of other insects. The giant descending neuron (GDN) of flies (Wyman et al., 1984) and the tritocerebral commissural giant (TCG) of locusts (Bicker and Pearson, 1983) are well studied examples. These neurons receive a variety of inputs, including mechanosensory input from the antennae. Mechanoreceptors located at the base of the antennae are the probable source of input to GDN and similar fly interneurons (Bacon and Strausfeld, 1986; Milde and Strausfeld, 1990). The antennal input to TCG seems to be similar to that of GDN (Bacon and Möhl, 1983). However, the behavioral significance of the antennae in controlling evasive behavior in these organisms is, at present, unclear.

Another prominent function for descending interneurons of insects is in aspects of flight control (Rowell, 1989; Gronenberg and Strausfeld, 1990). Behavioral studies have shown that mechanoreceptors at the base of the antennae can influence flight behavior in a variety of insects (Gewecke, 1974; Arbas, 1986), including cockroaches (Yagodin and Kovbasa, 1984), and so de-

scending mechanosensory interneurons must be involved. However, with the exception of TCG (Bacon and Möhl, 1983) and the dorsal cluster descending neurons (DCDN) in flies (Gronenberg and Strausfeld, 1990), little is known about how this type of input might influence motor centers.

\section{DMIs in relation to escape behavior}

Comer et al. (1988) demonstrated that, after severing the abdominal VNC and thus blocking all wind-evoked GI activity from reaching leg motor centers, cockroaches could still direct evasive responses away from wind puffs. Such non-GI escape responses to wind have characteristics suggesting that they are mediated by the DMI pathway: responses are two to three times longer in latency than GI-mediated responses, and they are abolished by antennal removal (see also Comer and Dowd, 1993; Stierle et al., 1994). However, it is important to note that the data presented here indicate that the DMI pathway probably does not normally function to control evasive responses to wind. Instead, its primary role seems to be that of a touch-sensory system.

Direct mechanical stimulation of the antennae activates the descending pathway at latencies considerably shorter than does wind stimulation (5-10 vs 20-30 msec; Burdohan and Comer, 1990) (see Figs. 2-4). Correspondingly, behavioral latencies in response to direct antennal contact by predators were found to be $\sim 15-20$ msec (Comer et al., 1994), so only touch activation of the DMIs is fast enough to explain initiation of escape by antennal receptors. This idea is supported further by experiments that demonstrate DMI activity precedes escape movements and that the pattern of DMI activation is correlated with the direction of the movements (Ye and Comer, 1996). 


\section{DMla-1}

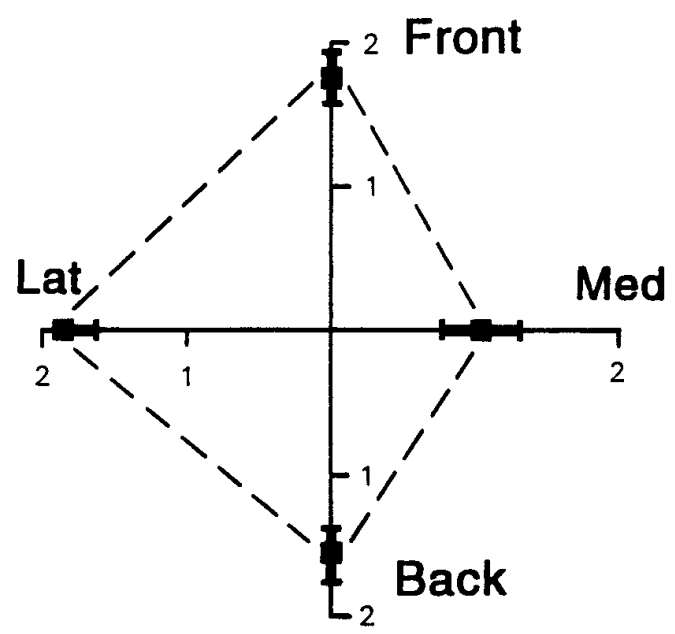

Contra Antenna

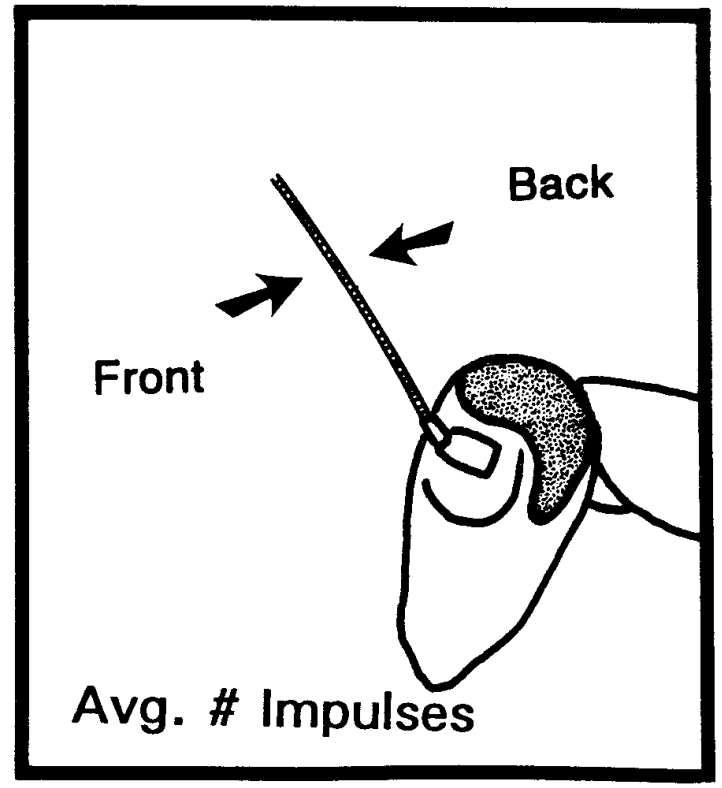

\section{DMlb-1}

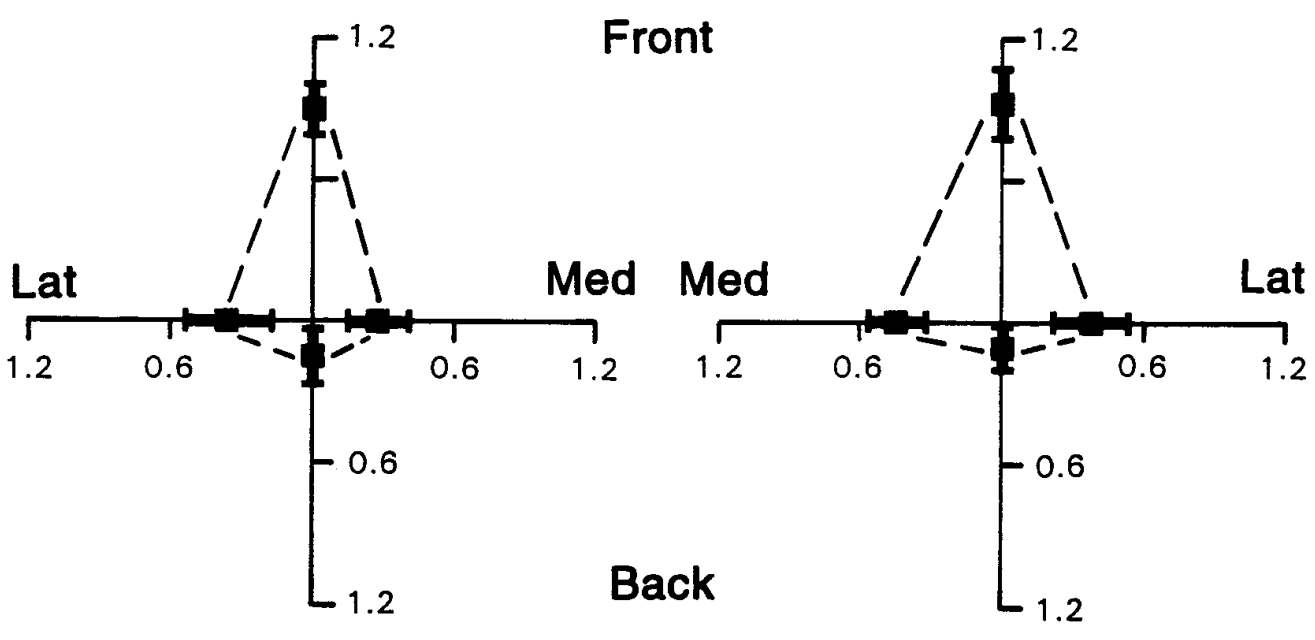

Contra Antenna

Ipsi Antenna

Figure 12. Directional sensitivity of DMIs. Directionality is plotted as average number of impulses recorded for taps delivered from each of the four directions tested: front (Front), back (Back), medial (Med), lateral (Lat). Front and back represent stimuli moving the flagellum parallel to the long axis of the body, as shown in the inset; medial and lateral were movements at right angles to those shown. Taps were delivered to deflect the antenna by the same amplitude $(1.0 \mathrm{~mm})$ and at the same rate $(0.1 \mathrm{~mm} / \mathrm{msec})$ on all trials. These values were chosen because they were optimal for activating the cells. Means for each direction (black squares) were derived by averaging responses for each animal and then calculating the grand mean across animals \pm SEM. Top, Response of DMIa-1 to mechanical stimulation of the contralateral antenna. Data from 11 cells, each from a different animal. Total number of trials $=277$. Bottom, Response of DMIb-1 to mechanical stimulation of each antenna. Data from eight cells, each from a different animal. Total number of trials $=329$. Left side shows responsiveness of cell to tapping the contralateral (Contra) antenna. Right side shows responsiveness to tapping the ipsilateral (Ipsi) antenna.

The present findings suggest that DMIs and GIs function as separate sensory-processing pathways. Camhi et al. (1978) have shown that the winds generated by toads during a predatory strike need only have a peak velocity of $\sim 22 \mathrm{~mm} / \mathrm{sec}$ for cockroaches to respond reliably with escape, but they must also have an abrupt onset (acceleration of $\sim 0.6 \mathrm{~m} / \mathrm{sec}^{2}$ ). The antennal pathway described here did not respond to winds considerably more intense in terms of both peak velocity and acceleration (Fig. 3). Thus, 
there seems to be a reasonable range within which wind signals can be handled reliably only by the cercal sensory system, and it indicates that the DMIs should not be involved in responses to large predators, such as toads. Conversely, the GIs are not implicated in responses to small predators detected by contact, because the GIs are not activated by direct mechanical stimulation of the antennae (Burdohan and Comer, 1990), and touch-evoked escape persists when the GIs have been ablated completely from the cord (Comer et al., 1994; Stierle et al., 1994). Thus, it seems that the GIs and DMIs provide separate channels of information flow to leg motor circuitry: from the filiform hairs on the cerci and from mechanoreceptors on the antennae, respectively. [It is important to note that the cerci and antennae are not the only receptive surfaces capable of activating evasive responses in cockroaches: direct mechanical stimulation of the pronotum and the metathoracic legs can elicit escape turning (Comer et al., 1988, 1994; Schaefer et al., 1994).]

Cockroach DMIs may be viewed as a sensory-processing pathway for the control of short-latency evasive behavior (Ye and Comer, 1996). Thus, they would be a second and separate escapeeliciting system from the well known GI pathway. The challenge now is to understand how information such as stimulus velocity and, especially, acceleration is encoded by the DMIs and then translated into patterns of motor discharge. A related question is to determine at what point touch information and wind-sensory information converge within the sensorimotor flow.

\section{REFERENCES}

Arbas EA (1986) Control of hindlimb posture by wind-sensitive hairs and antennae during locust flight. J Comp Physiol [A] 159:849-857.

Bacon JP, Altman JS (1977) A silver intensification method for cobaltfilled neurons in whole-mount preparations. Brain Res 138:359-363.

Bacon J, Möhl B (1983) The tritocerebral commissure giant (TCG) windsensitive interneurone in the locust. I. Its activity in straight flight. J Comp Physiol [A] 150:439-452.

Bacon JP, Strausfeld NJ (1986) The dipteran giant fibre pathway: neurons and signals. J Comp Physiol [A] 158:529-548.

Bicker G, Pearson KG (1983) Initiation of flight by an identified windsensitive neurone (TCG) in the locust. J Exp Biol 104:289-293.

Bräunig P, Pflüger H-J, Hustert R (1983) The specificity of central nervous projections of locust mechanoreceptors. J Comp Neurol 218:197-207.

Burdohan JA, Comer CM (1990) An antennal-derived mechanosensory pathway in the cockroach: descending interneurons as a substrate for evasive behavior. Brain Res 535:347-352.

Callec JJ, Sattelle DB (1973) A simple technique for monitoring the synaptic actions of pharmacological agents. J Exp Biol 59:725-738.

Camhi JM (1984) Neuroethology. Sunderland, MA: Sinauer.

Camhi JM (1988) Escape behavior in the cockroach: distributed neural processing. Experientia 44:401-408.

Camhi JM, Levy A (1988) Organization of a complex movement: fixed and variable components of the cockroach escape behavior. J Comp Physiol [A] 163:317-328.

Camhi JM, Levy A (1989) The code for stimulus direction in a cell assembly in the cockroach. J Comp Physiol [A] 165:83-97.

Camhi JM, Nolen TG (1981) Properties of the escape system of cockroaches during walking. J Comp Physiol [A] 142:339-346.

Camhi JM, Tom W (1978) The escape behavior of the cockroach Periplaneta americana. I. The turning response to wind puffs. J Comp Physiol [A] 128:193-201.

Camhi JM, Tom W, Volman S (1978) The escape behavior of the cockroach Periplaneta americana. II. Detection of natural predators by air displacement. J Comp Physiol [A] 128:203-212.

Comer CM (1985) Analyzing cockroach escape behavior with lesions of individual giant interneurons. Brain Res 335:342-346.

Comer CM, Dowd JP (1988) The neural basis of orienting behavior: a computational approach to the escape turn of the cockroach. Biol Cybern 60:37-48.
Comer CM, Dowd JP (1993) Multisensory processing for movement: antennal and cercal mediation of escape turning in the cockroach. In: Biological neural networks in invertebrate neuroethology and robotics (Beer RD, Ritzmann RE, McKenna T, eds), pp 89-112. New York: Academic.

Comer CM, Grobstein P (1981) Involvement of midbrain structures in tactually and visually elicited prey acquisition behavior in the frog, Rana pipiens. J Comp Physiol [A] 142:151-160.

Comer CM, Stubblefield GT (1988) Effects of lesioning individual giant interneurons on the direction of the escape-turning response in the adult cockroach, Periplaneta americana. Soc Neurosci Abstr 14:310.

Comer CM, Dowd JP, Stubblefield GT (1988) Escape responses following elimination of the giant interneuron pathway in the cockroach, Periplaneta americana. Brain Res 445:370-375.

Comer CM, Mara E, Murphy KA, Getman ME, Mungy MC (1994) Multisensory control of escape in the cockroach Periplaneta americana. II. Patterns of touch-evoked behavior. J Comp Physiol [A] 174:13-26.

Corey DP, Hudspeth AJ (1980) Mechanical stimulation and micromanipulation with piezoelectric bimorph elements. J Neurosci Methods 3:183-202.

DuLac S, Knudsen E (1990) Neural maps of head movement vector and speed in the optic tectum of the barn owl. J Neurophysiol 63:131-146.

Gewecke M (1974) The antennae of insects as air-current sense organs and their relationship to the control of flight. In: Experimental analysis of insect behavior (Barton Browne L, ed), pp 100-113. New York: Springer.

Gewecke M (1979) Central projection of antennal afferents for the flight motor in Locusta migratoria. Entomol Gen 5:317-320.

Gronenberg W, Strausfeld NJ (1990) Descending neurons supplying the neck and flight motor of Diptera: physiological and anatomical characteristics. J Comp Neurol 302:973-991.

Homberg U, Christensen TA, Hildebrand JG (1989) Structure and function of the deutocerebrum in insects. Annu Rev Entomol 34:477-501.

Jay MF, Sparks DL (1987) Sensorimotor integration in the primate superior colliculus. II. Coordinates of auditory signals. J Neurophysiol 57:35-55.

Levi R, Camhi JM (1994) Testing for a population vector code for wind direction in the cockroach giant interneurons. Soc Neurosci Abstr 20:1025.

Milde JJ, Strausfeld NJ (1990) Cluster organization and response characteristics of the giant fiber pathway of the blowfly Calliphora erythrocephala. J Comp Neurol 294:59-75.

Murrain M, Ritzmann RE (1988) Analysis of proprioceptive inputs to DPG interneurons in the cockroach. J Neurobiol 19:552-570.

Nye SW, Ritzmann RE (1992) Motion analysis of leg joints associated with escape turns of the cockroach Periplaneta americana. J Comp Physiol [A] 171:183-194.

Ritzmann RE (1993) The neural organization of cockroach escape and its role in context-dependent orientation. In: Biological neural networks in invertebrate neuroethology and robotics (Beer RD, Ritzmann RE, McKenna T, eds), pp 113-137. Boston: Academic.

Ritzmann RE, Pollack AJ (1986) Identification of thoracic interneurons that mediate giant interneuron-to-motor pathways in the cockroach. J Comp Physiol [A] 159:639-654.

Ritzmann RE, Pollack AJ (1990) Parallel motor pathways from thoracic interneurons of the ventral giant interneuron system of the cockroach, Periplaneta americana. J Neurobiol 21:1219-1235.

Ritzmann RE, Pollack AJ (1994) Responses of thoracic interneurons to tactile stimulation in the cockroach, Periplaneta americana. J Neurobiol 25:1113-1128.

Roeder K (1967) Nerve cells and insect behavior, 2nd Ed. Cambridge, MA: Harvard UP.

Rospars JP (1988) Structure and development of the insect antennodeutocerebral system. Int J Insect Morphol Embryol 17:243-294.

Rowell CHF (1989) Descending interneurones of the locust reporting deviation from flight course: what is their role in steering? J Exp Biol 146:177-194.

Schaefer PL, Kondagunta GV, Ritzmann RE (1994) Motion analysis of escape movements evoked by tactile stimulation in the cockroach Periplaneta americana. J Exp Biol 190:287-294.

Schaller D (1978) Antennal sensory system of Periplaneta americana (L.): distribution and frequency of morphologic types of sensilla and their sex-specific changes during postembryonic development. Cell Tissue Res 191:121-139. 
Spira MP, Parnas I, Bergmann F (1969) Organization of the giant axons of the cockroach, Periplaneta americana. J Exp Biol 50:615-627.

Stein BE, Meredith MA, Huneycutt WS, McDade L (1989) Behavioral indices of multisensory integration: orientation to visual cues is affected by auditory stimuli. J Cognit Neurosci 1:12-24.

Stierle IE, Getman M, Comer CM (1994) Multisensory control of escape in the cockroach. I. Initial evidence from patterns of wind-evoked behavior. J Comp Physiol [A] 174:1-11.

Strausfeld NJ, Bacon JP (1983) Multimodal convergence in the central nervous system of dipterous insects. Fortschr Zool 28:47-76.

Strausfeld NJ, Bassemir U, Singh RN, Bacon JP (1984) Organizational principles of outputs from dipteran brains. J Insect Physiol 30:73-93.

Stubblefield GT, Comer CM (1989) Organization of giant interneuron projections in thoracic ganglia of the cockroach Periplaneta americana. J Morphol 200:199-213.

Toh Y (1977) Fine structure of antennal sense organs of the male cockroach, Periplaneta americana. J Ultrastruct Res 60:373-394.

Toh Y (1981) Fine structure of sense organs on the antennal pedicel and scape of the male cockroach, Periplaneta americana. J Ultrastruct Res 77:119-132.
Tyrer NM, Gregory GE (1982) A guide to the neuroanatomy of locust subesophageal and thoracic ganglia. Philos Trans R Soc Lond [Biol] 297:91-123.

Westin J, Langberg JJ, Camhi JM (1977) Responses of giant interneurons of the cockroach Periplaneta americana to wind puffs of different directions and velocities. J Comp Physiol [A] 121:307-324.

Wyman RJ, Thomas JB, Salkoff L, King DG (1984) The Drosophila giant fiber system. In: Neural mechanisms of startle behavior (Eaton RC, ed), pp 133-161. New York: Plenum.

Yagodin SV, Kovbasa SI (1984) The flight maintenance mechanism in the cockroach Periplaneta americana. J Comp Physiol [A] 155:697-712.

Ye S, Comer CM (1994) Visual cues may influence the escape response of cockroaches. Soc Neurosci Abstr 20:1025.

Ye S, Comer CM (1996) Correspondence of escape-turning behavior with activity of descending mechanosensory interneurons in the cockroach, Periplaneta americana. 16:5844-5853.

Zill SN, Moran DT (1981) The exoskeleton and insect proprioception. I. Responses of tibial campaniform sensilla to external and musclegenerated forces in the American cockroach, Periplaneta americana. J Exp Biol 91:1-24. 